\title{
Peningkatan Pengetahuan Ibu Hamil Trimester III Melalui Edukasi Manfaat Jus Buah Bit untuk Pencegahan Anemia di Desa Kuala Air Hitam
}

\author{
Julina Br Sembiring 1*, Dalimawaty Kadir² \\ ${ }^{1}$ Institut Kesehatan Helvetia, Medan, Indonesia \\ ${ }^{2}$ STKIP Asy-Syafi'iyah Internasional, Medan, Indonesia \\ *Corresponding Author: azkatepu @gmail.com
}

Info Artikel Diterima : $16 / 11 / 2021$ Direvisi: $18 / 11 / 2021 \quad$ Disetujui: $22 / 11 / 2021$

\begin{abstract}
The World Health Organization (WHO) states that anemia is a serious global public health problem that especially affects women of childbearing age and pregnant women. The prevalence of anemia in women of childbearing age is $29.9 \%$, in pregnant women $36.5 \%$, in non-pregnant women $29.6 \%$. Prevalence varies widely between countries and regions. Beetroot or also called Beta Vulgaris L. is a kind of tuber plant that is reddish purple in color. Shaped like a potato. Usually beets are consumed by juice or processed again into a meal with a soft texture. Anemia in pregnancy is very dangerous for the mother and the fetus. The impact of anemia on pregnant women is abortion, premature delivery, inhibition of fetal growth and development in the womb, susceptible to infection, antepartum bleeding, premature rupture of membranes, during delivery can cause His disorder, the first stage of labor can last a long time and neglected parturition occurs. In parturition, uterine subinvolution occurs which can cause postpartum hemorrhage, facilitate puerperal infection, and reduce breast milk production. The form of activity used in community service is the counseling method with lectures and questions and answers, by measuring knowledge, pre and post tests are carried out. The conclusion is that there is an increase in knowledge after being given education to mothers third trimester pregnant.
\end{abstract}

Keywords: Beetroot, Anemia, Pregnant Women

\begin{abstract}
Abstrak. World Health Organization (WHO) menyatakan bahwa anemia adalah masalah kesehatan masyarakat global yang serius yang khususnya menyerang wanita usia subur dan wanita hamil. Prevalensi anemia pada wanita usia subur $29,9 \%$, pada wanita hamil $36,5 \%$, pada wanita tidak hamil 29,6\%. Prevalensi sangat bervariasi antar negara dan wilayah. Buah bit atau disebut juga dengan Beta Vulgaris L.merupakan tanaman sejenis umbi yang berwarna ungu kemerahan. Bentuknya meyerupai kentang. Biasanya buah bit dikonsumsi dengan cara dijus atau diolah lagi menjadi santapan dengan tekstur lembut. Anemia pada kehamilan sangat berbahaya bagi ibu dan janinnya. Dampak anemia pada ibu hamil adalah abortus, persalinan premature, hambatan tumbuh kembang janin dalam rahim, rentan terkena infeksi, perdarahan antepartum, ketuban pecah dini, saat persalinan dapat mengakibatkan gangguan His, kala pertama dalam persalinan dapat berlangsung lama dan terjadi partus terlantar, pada kala nifas terjadi subinvolusio uteri yang dapat menimbulkan perdarahan postpartum, memudahkan infeksi puerperenium, serta berkurangnya produksi ASI Tujuan pengabdian adalah dapat memberikan edukasi pada ibu hamil tentang pemanfaatan buah Bit (Beta vulgaris L) dapat meningkatkan kadar hemoglobin di Klinik ina Karya Medan. Bentuk kegiatan yang digunakan dalam pengabdian masyarakat adalah metode penyuluhan dengan ceramah dan tanya jawab, dengan mengukur pengetahuan dilakukan pre dan post test. Kesimpulan adanya peningkatan pengetahuan setelah diberikan edukasi pada ibu hamil Trimester III.
\end{abstract}

Kata Kunci: Buah Bit, Anemia, Ibu Hamil

How to Cite: How to Cite: Sembiring, J. B., \& Kadir, D. (2021). Peningkatan Pengetahuan Ibu Hamil Trimester III Melalui Edukasi Manfaat Jus Buah Bit untuk Pencegahan Anemia di Desa Kuala Air Hitam. Prima Abdika: Jurnal Pengabdian Masyarakat, 1(4), https://doi.org/10.37478/abdika.v1i4.1324

Copyright (c) 2021 Julina Br Sembiring, Dalimawaty Kadir. This work is licensed under a Creative Commons Attribution-ShareAlike 4.0 International License.

\section{Pendahuluan}

Kehamilan beresiko tinggi memiliki tanda bahaya dalam kehamilan diantaranya adalah perdarahan pervaginam, sakit kepala hebat, sering berdebar-debar, sesak napas dan cepat lelah. Sesak napas dan jantung berdebar biasa dialami oleh sebagian besar ibu hamil. Sesak napas dan jantung berdebar-debar saat hamil mengindikasikan beberapa kemungkinan salah satunya yaitu anemia (F., 2019) . Anemia adalah kondisi dimana sel darah merah menurun atau menurunnya hemoglobin, sehinggga kapasitas 
daya angkut oksigen untuk kebutuhan organ-organ vital pada ibu dan janin menjadi berkurang (Tarwoto $\mathrm{W}, 2017$ ).

Anemia ialah kondisi yang menggambarkan kadar hemoglobin atau jumlah eritosit dalam darah tidak normal atau rendah. Hemoglobin berfungsi membawa oksigen (oksihemoglobin) dan diedarkan ke seluruh tubuh untuk kebutuhan metabolisme. Derajat anemia pada ibu hamil dapat diklasifikasikan menjadi 4 bagian, yaitu: Tidak anemia : Hb $11 \mathrm{gr} \%$, anemia ringan : $\mathrm{Hb}$ 9-10 gr\%, anemia sedang : $\mathrm{Hb} 7-8$ gr\%, anemia berat : $\mathrm{Hb}<7 \mathrm{gr} \%$. Anemia kehamilan disebut "potentional danger to mother and child" (potensi membahayakan ibu dan anak), karena itulah anemia memerlukan perhatian serius dari semua pihak yang terkait dalam pelayanan kesehatan (Fitria, 2019).

Berdasarkan data dari World Health Organization (WHO) Anemia adalah masalah kesehatan masyarakat global yang serius yang khususnya menyerang wanita usia subur dan wanita hamil. Prevalensi anemia pada wanita usia subur $29,9 \%$, pada wanita hamil $36,5 \%$ dan pada wanita tidak hamil 29,6\%. Prevalensi sangat bervariasi antar negara dan wilayah. Di antara wanita usia reproduksi, prevalensi tertinggi di wilayah Asia Tengah dan Asia Selatan dan Afrika sub-Sahara dan terendah di Amerika Utara dan Eropa (World Health Statistics, 2021).

Hasil dari data Riset Kesehatan Dasar (Riskesdas) Tahun 2018, tentang proporsi anemia ibu hamil pada tahun 2013 yang mengalami anemia sebanyak 37,1\% dan mengalami peningkatan pada tahun 2018 sebanyak $48,9 \%$ ibu hamil yang mengalami anemia. Data anemia ibu hamil menurut umur, pada umur 15-24 tahun (33,7\%), 25-34 tahun (33,6\%), umur 35-44 tahun (24\%), sedangkan diumur 45-54 tahun (84,6\%), untuk mencegah anemia setiap ibu hamil diharapkan mendapatkan tablet tambah darah (TTD) minimal 90 tablet selama kehamilan dengan dosis 60 mg (Rikesdas RI, 2018).

Berdasarkan data yang diperoleh dari Kota Medan tahun 2018 menunjukkan dari 39.240 ibu hamil terdapat 780 ibu hamil yang mengalami anemia. Angka kejadian anemia di Indonesia masih tinggi dikarenakan pencegahan dan penanganan belum dilakukan sebelum masa kehamilan. Asuhan pelayanan pada kehamilan yaitu mencegah komplikasi ada masa kehamilan maupun persalinan dengan pemeriksaan darah yang dilakukan minimal dua kali selama kehamilan, yaitu pada trimester satu dan tiga, kunjungan pemeriksaan kehamilan minimal empat kali selama kehamilan yaitu satu kali pada trimester pertama, satu kali pada trimester kedua dan dua kali pada trimester ketiga (Anwar, 2019).

Anemia pada kehamilan sangat berbahaya bagi ibu dan janinnya. Dampak anemia pada ibu hamil adalah abortus, persalinan premature, hambatan tumbuh kembang janin dalam rahim, rentan terkena infeksi, perdarahan antepartum, ketuban pecah dini, saat persalinan dapat mengakibatkan gangguan His, kala pertama dalam persalinan dapat berlangsung lama dan terjadi partus terlantar, pada kala nifas terjadi subinvolusio uteri yang dapat menimbulkan perdarahan postpartum, memudahkan infeksi puerperenium, serta berkurangnya produksi ASI (Pratami E, 2016).

Pencegahan anemia pada ibu hamil dapat dilakukan dengan dua cara yaitu secara farmakologi dan non farmakologi, cara farmakologis yaitu dengan 
pemberian $60 \mathrm{mg}$ tablet $\mathrm{Fe}$ dan 50 nano gram asam folat selama kehamilan (Nursalam, Ho, Widyanti, \& Agustini, 2016). Adapun cara non farmakologis adalah dengan mengkonsumsi makanan yang bergizi seperti daging merah, olahan susu sapi, hati sapi/ayam, makanan laut, kacang-kacangan, sayuran berdaun hijau,dan buah-buahan, diantara semua, umbi buah bit adalah salah satu buah yang dapat mencegah anemia (Gustina, Yuria, \& Dita, 2020).

Buah Bit adalah tanaman yang berasal dari keluarga Amaranthaceae Chenopodiaceae. Yang artinya, buah bit masih satu keluarga dengan sayuran lobak dan sayuran berakar lainnya. Umumnya buah ini hanya digunakan akarnya saja yang terasa manis untuk obat kesehatan, namun lama kelamaan, daging buah dan daunnya juga dikonsumsi. Buah bit atau disebut juga dengan Beta Vulgaris L.merupakan tanaman sejenis umbi yang berwarna ungu kemerahan. Bentuknya meyerupai kentang. Biasanya buah bit dikonsumsi dengan cara dijus atau diolah lagi menjadi santapan dengan tekstur lembut (Anwar, 2019).

Kandungan dari buah bit adalah asam folat yang terdapat dalam bit sebesar 34\%, Kalium sebesar 14,8\%, Serat pangan sebesar 13,6\%, Vitamin C sebesar 10,2\%, Zat besi sebesar 7,4\%, Tembaga sebesar 6,5\%, Fosfor sebesar $6,5 \%$, Triptofan sebesar 1,4\%, Caumarin, dan zat antioksidan (Gustina et al., 2020).

Berdasarkan hasil survey yang di lakukan Di Desa Kwala Air Hitam pada bulan juli Tahun 2021, dan melakukan pemeriksaan HB pada ibu hamil trimester III menggunakan easy touch $\mathrm{GcHb}$ dan didapatkan hasil bahwa dari 5 ibu hamil trimester III terdapat sebanyak 3 ibu hamil yang mengalami anemia, 2 diantara ibu hamil yang mengalami anemia Bernama sari dengan kadar HB 10,2 gr/dl, dan uci dengan kadar HB 10,4 gr/dl, mengatakan merasa bosan jika terus mengkonsumsi obat-obatan, dan ibu juga tidak mengetahui bahwa hal tersebut dapat menyebakan kekurangan hemoglobin pada ibu hamil yang dapat berdampak tidak baik pada ibu dan janin, dan ibu tersebut juga jarang mengkonsumsi buah-buahan padahal buah sangat banyak manfaat nya untuk tubuh seperti buah bit.

Buah bit memiliki banyak manfaat terutama untuk peningkatan kadar hemoglobin dalam tubuh karena buah bit memiliki kandungan zat besi dan asam folat, sehigga ibu hamil anya fokus dalam pengobatan farmakologi dan tidak memahami cara yang dapat meningkatkan kadar hemoglobin selain tablet Fe. Sehingga dari survey yang dilakukan sangat penting sekali dilakukan penyuluhan tentang manfaat buah Bit di Desa Kwala Air Hitam. Tujuan kegiatan ini sepenuhnya di apresiasi oleh Bidan Desa Kwala Air Hitam agar masyarakat khususnya ibu hamil mengerti cara pengobatan non farmakologi untuk meningkatkan HB pada ibu hamil. Setelah dilakukannya penyuluhan diharapkan seluruh ibu hamil yang ada di Desa Kwala Air Hitam memahami dalam pencegahan dan pengobatan Anemia dengan mengkonsumsi Buah Bit.

\section{Metode Pelaksanaan}

Dalam kegiatan penyuluhan ini sasaran peserta adalah ibu hamil Trimester III yang ada Di Desa Kwala Air Hitam sebanyak 12 orang. Metode yang digunakan berupa Penyuluhan ibu hamil tentang anemia kehamilan, tanda dan gejala, resiko dan komplikasi , pencegahan serta manfaat Buah Bit 
(Beta vulgaris L) dapat meningkatkan kadar hemoglobin pada ibu hamil anemia. Sehingga nantinya setelah dilakukan penyuluhan, ibu hamil dapat mengerti dan selanjutnya bidan desa Kwala Air Hitam dapat mengedukasi ibu hamil tentang pencegahan dan pengobatan Anemia pada ibu hamil dengan mengkonsmsi bah Bit. Adapun tahapan kegiatan edukasi atau penyuluhan untuk meningkatkan ilmu pengetahuan ibu hamil tentang pencegahan anemia dengan menggunakan pengobatan non farmakologi dengan megkonsumsi Buah Bit sebagai berikut

a. Tahap persiapan

Tahapan persiapan yaitu koordinasi tempat, survey ada tidaknya masalah anemia, pengurusan izin dan pembuatan kuesioner serta leaflet untuk kegiatan edukasi tentang anemia dalam kehamilan, pencegahan dan penanganan dengan cara pemanfaatan Bit merah yang disajikan dalam bentuk jus. Adapun bahan yang digunakan dalam pembuatan jus buah bit adalah 1 buah bit yang sudah dipotong-potong (100 gram), 1 gelas air matang $110 \mathrm{ml}$, dan 35 gram gula pasir dan di blender dengan jumlah jus $200 \mathrm{cc} / \mathrm{ml}$.

\section{b. Tahap pelaksanaan}

Tahap pelaksanaan kegiatan dilakukan selama 1 hari tanggal 10 Oktober 2021 yang bertempat di Desa Kwala Air Hitam dengan menjalankan protokol kesehatan pencegahan Covid-19. Tanggal 10 Oktober 2021, dilakukan pembagian kuesioner pre tes untuk mengukur pengetahuan ibu hamil. Penyuluhan juga dilaksanakan pada tanggal tersebut pukul 13.00 wib, dengan metode ceramah yang menekankan materi tentang anemia pada ibu hamil Timester III dan edukasi pemanfaatan buah Bit untuk meningkatkan kadar hemoglobin pada ibu hamil anemia. Selain itu metode yang digunakan adalah tanya jawab agar peserta lebih interaktif dan memahami materi yang disampaikan. Kemudian dilakukan pembagian kuesioner post tes untuk mengukur tingkat pengetahuan ibu setelah dilakukan penyuluhan.

c. Evaluasi

Kegiatan penyuluhan dihadiri oleh seluruh ibu hamil yang ada di Desa Kwala Air Hitam, Bisa dilihat dari peserta yang hadir sebanyak 12 orang. Pengaturan tempat sesuai dengan rencana kegiatan. Perlengkapan alat dan bahan penyuluhan sudah tersedia dan digunakan sebagaimana mestinya. Cuaca juga sangat mendukung. Bahasa yang digunakan komunikatif dalam penyampaian sehingga peserta dapat memahami materi yang telah disampaikan oleh tim pelaksana kegiatan penyuluhan. Sesi tanya jawab dan berlangsung aktif dan antusias ditandai dengan peserta banyak pertanyaan terhadap materi yang disampaikan. Pelaksanaan kegiatan berakhir 15.00 wib sesuai dengan jadwal telah yang direncanakan. Kegiatan berlangsung aman dan lancar.

\section{Hasil dan Pembahasan}

Kegiatan pengabdian masyarakat dengan memberikan edukasi pencegahan anemia dengan mengkonsumsi buah bit dilakukan tanggal 10 oktober 2021 jam 13.00 wib. Kegiatan penyuluhan ini selain dihadiri oleh ibu hamil juga dihadiri oleh bidan desa Kwala Air Hitam. Desa Kwala Air Hitam berada di Kecamatan Selesai Kabupaten Langkat. Sebelum dilakukan 
penyuluhan ada pretest yang ditujukan kepada ibu hamil untuk dijawab. Ibu hamil antusias menjawab pertanyaan yang diberikan Kegiatan ini dilakukan dengan membagikan kuesioner yang di bagikan kepada ibu hamil edukasi pemanfaatan Buah Bit (Beta vulgaris L) terhadap peningkatan kadar hemoglobin pada ibu hamil anemia. Kemudian dilakukan penyuluhan dan peserta mendengarkan dan memperhatian ketika kegiatan berlangsung. Setelah kegiatan penyuluhan seleai dilakukan. Tim penyuluhan kembali memberikan kuesioner Post Test tentan materi penyuluhan sebelumnya yang telah diberikan.

Maka dari itu diperoleh hasil pengetahuan ibu hamil pada pengujian pretest didapatkan pengetahuan baik sebanyak 3 orang $(25 \%)$ dan pengetahuan Kurang sebanyak 9 orang $(75 \%)$. Setelah diberikan penyuluhan pengetahuan ibu hamil saat pengujian posttes diperoleh hasil pengetahuan baik sebanyak 11 orang $(91,7 \%)$ kurang 1 orang $(8,3 \%)$. Pada saat penyuluhan peserta sangat antusias mengikuti kegiatan ini dan peserta sangat aktif bertanya tentang hal-hal yang kurang jelas tentang materi yang disampaikan. Upaya yang dilakukan oleh tim

pengabdian ini terbukti meningkatkan pemahaman dan wawasan ibu hamil tentang manfaat buah bit (Beta vulgaris L) terhadap peningkatan kadar hemoglobin pada ibu dengan anemia di Desa Kwala Air Hitam.

Buah bit adalah tanaman yang berasal dari keluarga AmaranthaceaeChenopodiaceae. Yang artinya, buah bit masih satu keluarga dengan sayuran lobak dan sayuran berakar lainnya. Umumnya buah ini hanya digunakan akarnya saja yang terasa manis untuk obat kesehatan, namun lama kelamaan, daging buah dan daunnya juga dikonsumsi. Buah bit atau disebut juga dengan Beta Vulgaris L, merupakan tanaman sejenis umbi yang berwarna ungu kemerahan. Bentuknya meyerupai kentang. Biasanya buah bit dikonsumsi dengan cara dijus atau diolah lagi menjadi santapan dengan tekstur lembut. (Amila, Siti Maimunah, Henny Syapitri, Jon Kenedy Marpaung, 2021) Manfaat dan kandungan buah bit, Jumlah kadar asam folat yang terdapat dalam bit sebesar 34\%, manfaatnya untuk menumbuhkan dan mengganti sel yang rusak, mencegah kecacatan pada janin dan dapat menunjang perkembangan otak pada janin. Kalium sebesar 14,8\%, manfaatnya menyeimbangkan kondisi cairan dalam tubuh. Serat pangan sebesar 13,6\%, manfaatnya memperlancar proses pencernaan dan menyehatkan organ pencernaan.Vitamin C sebesar 10,2\%, manfaatnya menjaga daya tahan tubuh dan merangsang pembentukan sel dan jaringan baru. Magnesium sebesar 9,8\%, manfaatnya menjaga fungsi otot dan sistem syaraf. Zat besi sebesar 7,4\%, manfaatnya membantu metabolisme energi dan mengikat oksigen dalam darah. Tembaga sebesar 6,5\%, manfaatnya membantu pembentukan sel darah merah.Fosfor sebesar $6,5 \%$, manfaatnya untuk memperkuat tulang. Triptofan sebesar 1,4\%, manfaatnya untuk mendukung pertumbuhan anak dan mempercepat penyembuhan saat sakit. Caumarin, berfungsi untuk mencegah munculnya sel tumor Betasianin, berfungsi untuk mencegah munculnya sel kanker. (Amila, Siti Maimunah, Henny Syapitri, Jon Kenedy Marpaung, 2021)

Buah bit memiliki banyak kelebihan bagi kesehatan maupun pengobatan. Kandungan betasinin pada buah bit bermanfaat sebagai anti kanker, karena zat tersebut dapat menghancurkan sel tumor dan kanker. 
Buah bit (Beta Vulgaris) memiliki kandungan asam folat sebesar $109 \mathrm{mg}$, dan vitamin $\mathrm{C}$ sebesar 10,0 Anemia yang terjadi pada ibu hamil juga dapat membahayakan janin yang dikandungnya. Buah bit memiliki kandungan asam folat dan zat besi yang sangat dibutuhkan oleh tubuh, sehingga buah bit sangat baik dikonsumsi untuk pencegahan dan pengobatan anemia, karena penyebab terjadinya anemia dalam tubuh disebabkan oleh kekurangan zat besi dan asam folat didalam tubuh terutama pada saat kehamilan agar mencegah anemia, Ancaman yang ditimbulkan oleh anemia pada janin adalah resiko terjadinya kematian intra, uteri, resiko terjadinya abortus, berat badan lahir rendah, resiko terjadinya cacat bawaan. Semakin banyak orang menggali informasi, maka akan semakin meningkat pengetahuan seseorang. Pengetahuan seseorang bisa didapat melalui media elektronik, media cetak, Komunikasi informasi dan edukasi, seminar dan penyuluhan. Menurut asumsi tim pengabdian masyarakat, ibu hamil rentan terjadi resiko dan komplikasi selama kehamilan. Oleh karena itu untuk mencegah hal tersebut ibu hamil mesti meningkatkan pengetahuan sehingga akan ada perubahan perilaku dalam menjaga kesehatan nya selama hamil. (Nursalam et al., 2016)

Hasil kegiatan pretest dan posttest penyuluhan ini mempunyai hasil yang berbeda. Setelah dilakukan Penyuluhan ada peningkatan pengetahuan pada ibu hamil tentang edukasi mengkonsumsi Buah bit terhadap pencegahan anemia dan peningkatan HB pada ibu hamil. Peserta juga merasakan manfaat setelah dilakukan penyuluhan dan mereka memahami tentang pengobatan non farmakologi dalam mencegah anemia. Kegiatan ini berlangsung dengan kondusif dan mendapatkan antusias yang sangat baik oleh ibu hamil dan bidan dea di desa kwala Air Hiam tersebut.

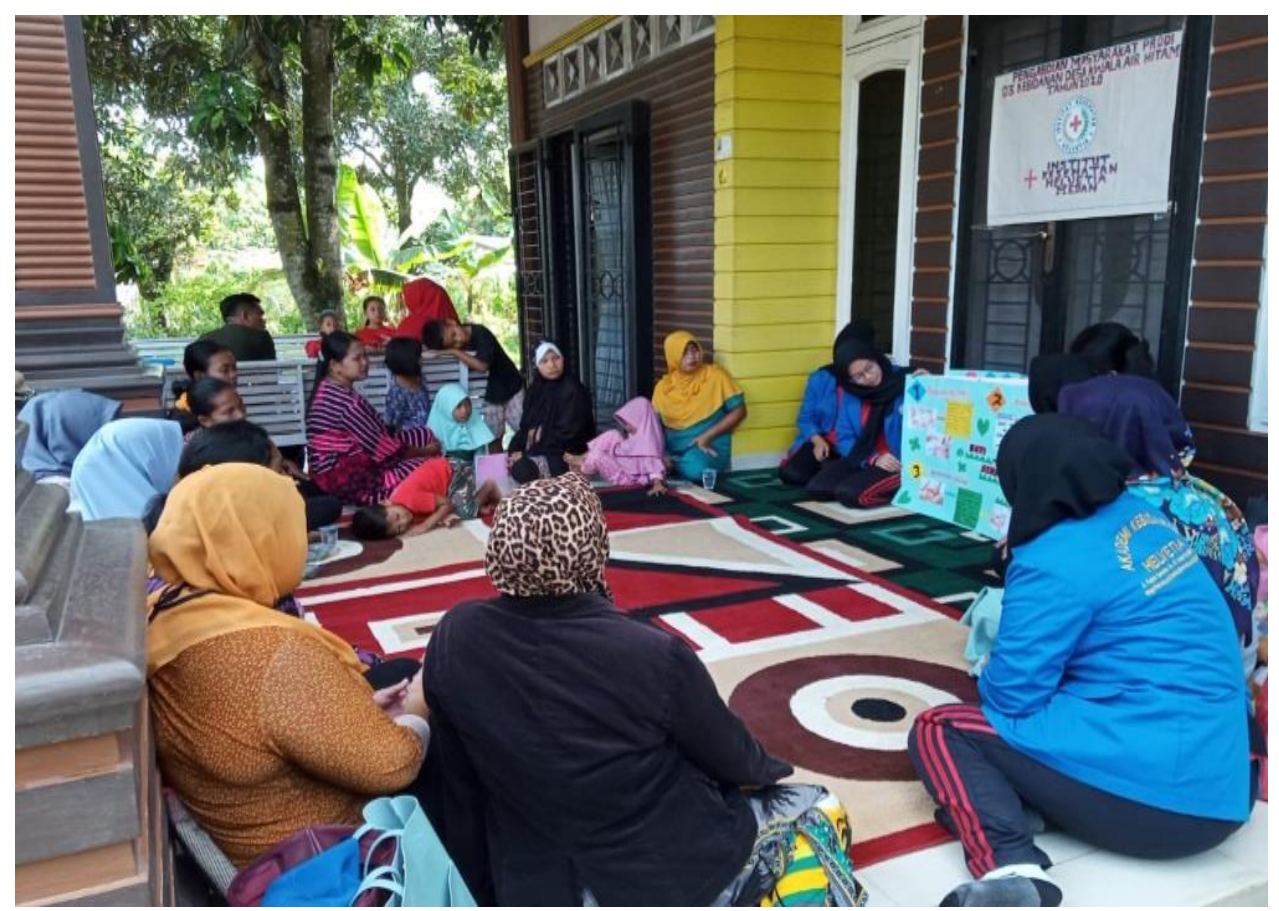

Gambar 1. Kegiatan Penyuluhan 


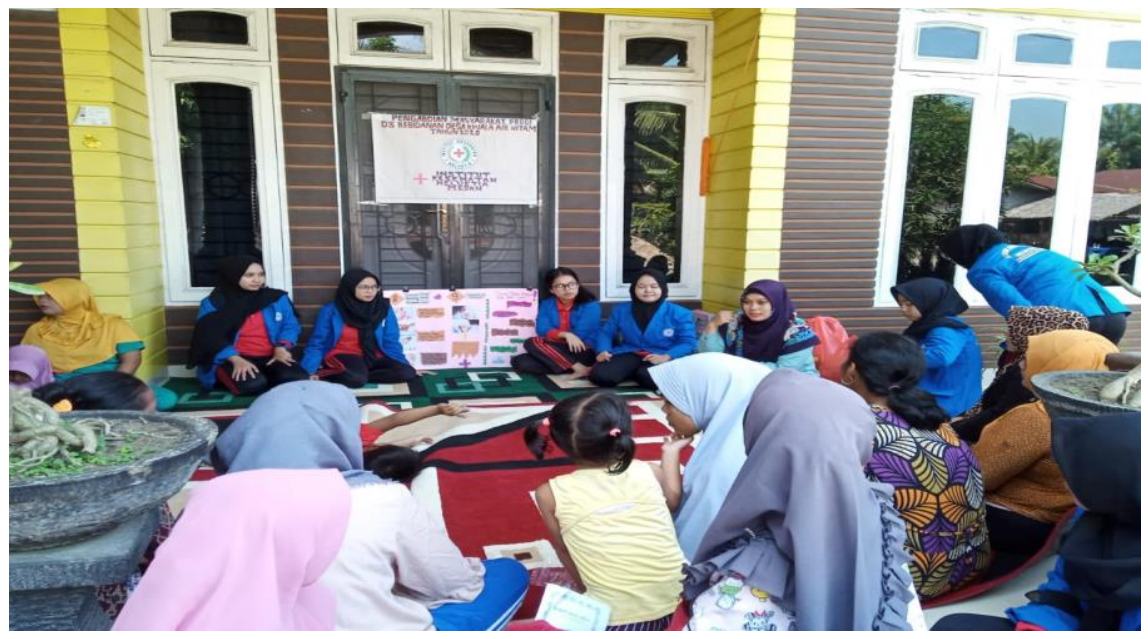

Gambar 2 . Tanya Jawab dan Membagikan Angket Post Test

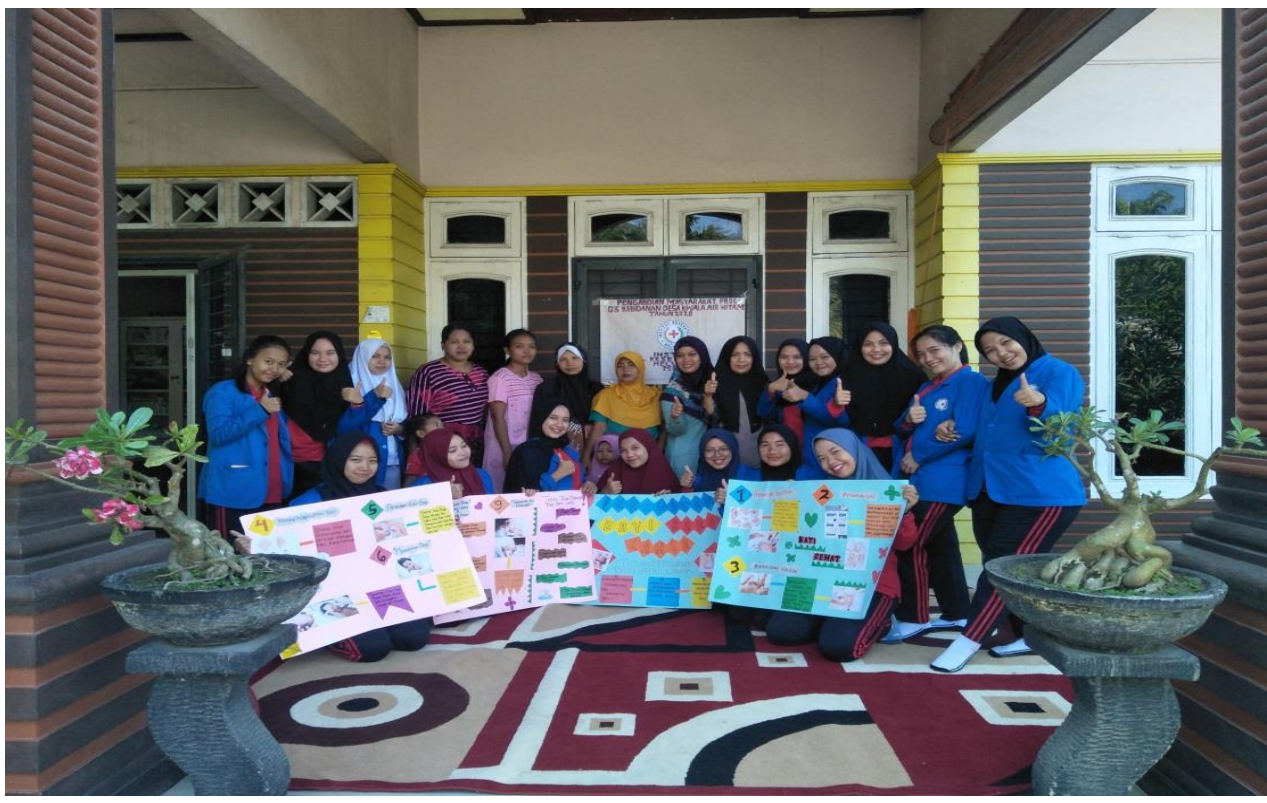

Gambar 3. Foto Bersama Setelah Penyuluhan

\section{Simpulan dan Tindak Lanjut}

Kegiatan Pelatihan berlangsung sesuai rencana dan mendapat respon yang baik dari masyarakat sehingga ibu hamil mengetahui manfaat buah bit untuk pencegahan dan pengobatan anemia. Terdapat peningkatan pengetahuan ibu hamil mengenai pencegaan anemia terutama pada masa kehamilan dan terdapat peningkatan kesadaran untuk dapat melakukan pencegahan kondisi anemia dengan mengkonsumsi buah bit. Berdasarkan hasil evaluasi selama kegiatan penyuluhan perlu ditindaklanjuti beberapa hal yaitu Perlunya peningkatan peran tenaga kesehatan dalam memberikan layanan edukasi kesehatan pada ibu hamil mengenai pengobatan nonfarmakologi. Ibu hamil harus secara rutin memeriksakan kehamilan dan melakukan Pemeriksaan hemoglobin berkala sebagai tindakan pencegahan anemia. Perlu adanya kerjasama lebih lanjut antara petugas kesehatan setempat untuk melakukan penyuluhan tentang pengobatan anemia selain denan mengkonsumsi buah bit. 


\section{Daftar Pustaka}

Amila, Siti Maimunah, Henny Syapitri, Jon Kenedy Marpaung, V. I. G. (2021). mengenal si cantik bit dan manfaatnya (1st ed.; Y. Umaya, ed.). Malang: Ahlimedia press.

Anwar, D. (2019). Faktor-Faktor Yang Mempengaruhi Kejadian Anemia Pada Ibu Hamil Trimester III Di Wilaya Kerja Puskesmas Johor Tahun 2019. JURNAL ILMIAH KOHESI Vol. 3 No. 4 Oktober 2019, 3(4), 37-43.

F., A. M. P. (2019). Patologi Kehamilan Memahami Berbagai Penyakit \& Komplikasi KehamilanNo Title. Yogyakarta: Pustaka Baru Press.

Fitria. (n.d.). Manfaat Buah Bit (Beta vulgaris) Terhadap Peningkatan Kadar Haemoglobin (Hb) Ibu Hamil. 53(9):1689-99.

Gustina, I., Yuria, M., \& Dita, P. S. (2020). Manfaat Pemberian Jus Buah Bit Pada Ibu Hamil Dengan Anemia Terhadap Peningkatan Kadar Hemoglobin Di Wilayah Kerja Puskesmas Kec. Jatinegara Dan Puskesmas Kec. Kramat Jati Tahun 2019. Jurnal Ilmiah Bidan, V(1), 36-44.

Nursalam, Ho, W., Widyanti, A., \& Agustini, N. (2016). EFEKTIVITAS PEMBERIAN JUS BUAH BIT TERHADAP KADAR HEMOGLOBIN IBU HAMIL DENGAN ANEMIA. Jurnal Keperawatan Indonesia, 25(3), 145-151.

Pratami E. (2016). Evidance based dalam kebidanan. Jakarta: EGC.

Rikesdas RI. (2018). Laporan Riset Kesehatan Dasar Provinsi Sumatera Utara tahun 2018. In Balitbangkes.

Tarwoto W. (2017). Buku Saku Anemia Pada Ibu Hamil Konsep Dan Penatalaksanaan. Jakarta: CV. Trans Info Media.

World Health Statistics. (2021). Monitoring Health For The SDGs Sustainable Development Goals. World Heal Organ. 